\title{
TWO-BODY ABRASION RESISTANCE OF HIGH-CARBON METASTABLE AUSTENITIC STEELS
}

\author{
${ }^{1}$ Jerome INGBER, ${ }^{2}$ Stephanie LIPPMANN, ${ }^{1}$ Maik KUNERT \\ ${ }^{1}$ University of Applied Sciences Jena, Jena, Germany, EU, mailto:Jerome.Ingber@eah-jena.de \\ ${ }^{2}$ Friedrich-Schiller-Universität Jena, Otto Schott Institute of Materials Research, Chair of Metallic Materials, \\ Jena, Germany, EU
}

https://doi.org/10.37904/metal.2021.4152

\begin{abstract}
This study presents the results of two-body abrasion tests on several high-carbon low-alloy steels initially consisting of a dual-phase microstructure containing metastable austenite and thermally induced plate martensite. The wear behavior of these metastable austenitic steels (MAS) is compared to commercial wearresistant steels. Some tested MAS showed specific wear rates (SWR) that are more than three times lower compared to that of a martensitic 30MnB5 (1.5531) and an austenitic X120Mn12 (1.3401) steel and even more than five times lower than the SWR of Hardox 450. Pre- and post-wear hardness measurements indicate that low wear rates in MAS are related to hardness increase during wear. MAS with post-wear hardness in the range of $900-1000 \mathrm{HV}$ achieved the lowest SWR. A further increased post-wear hardness up to $1250 \mathrm{HV}$ proved to be not beneficial and led to an increasing SWR. XRD measurements show significant changes in the phase fractions of the MAS sub-surface region due to an austenite-martensite phase transformation. SEM micrographs also show severe plastic deformation in the sub-surface layer and the wear tracks.
\end{abstract}

Keywords: High-carbon steel, abrasive wear, austenite, martensite

\section{INTRODUCTION}

Depending on the composition, austenite can be manipulated to be either stable (advantage of the high work hardening) or metastable (advantage of hardening by phase transformation). In recent years, there has been an increasing interest in using metastable austenite in multiphase steels (e.g. automotive TRIP-steels, nanobainitic steels) due to the deformation-induced formation of martensite [1] and its large work hardening capacity [2]. Metastable austenite is gaining attention in the development of highly wear-resistant steels [3-8]. Traditionally, high wear resistance is achieved by a high hardness of the steels as a surface can only be scratched by an abrasive particle if the abrasive hardness is 1.2 times the hardness of the surface [9]. Therefore, it is not surprising that many commercial wear-resistant steels have a fully martensitic microstructure to achieve the highest possible hardness. The hardness of martensite increases with the carbon content [2] as the dislocation movement is impeded by higher intrinsic stresses through greater lattice distortions. However, a major problem with increasing the carbon concentration is a decreasing fracture toughness which must be considered as a low toughness leads to greater wear [9]. Chintha [9] points out that material deformed at the surface is more likely to be detached in brittle steels because the work hardening capacity is lower compared to a tougher steel with the same composition. This is in good agreement with Bakshi [8] who reports that changing the microstructure from martensitic to pearlitic or bainitic can reduce the wear rate since the underlying mechanism of material removal changes with microstructure. Other researchers have shown that an austenitic microstructure can be even more suitable for wear application compared to bainitic microstructure [6] by inducing an austenite-martensite transformation during wear. The martensitic layer formed during wear in the sub-surface region shows hardness up to $1100 \mathrm{HV}$. Such a transformation could be used to combine austenitic toughness with high-carbon martensitic hardness. 
The objective of this study was to analyse the resistance of some high-carbon metastable austenitic steels (MAS) against two-body abrasive wear and to investigate the influence of the deformation-induced transformation in the sub-surface region.

\section{EXPERIMENTAL PROCEDURES}

\subsection{MATERIALS}

Table 1 indicates the chemical compositions of the MAS and their designations. The steels were melted in an induction furnace. Every heat treatment procedure was carried out using argon atmosphere to prevent decarburization. Chemical compositions were determined using optical emission spectroscopy (SPECTROMAXx; Spectro Analytical Instruments). The carbon content is kept constant at around $1.25 \mathrm{wt} \%$ for all composition. This is necessary to lower the martensite start temperature and conserve a high fraction of austenite after quenching. S1 to S4 contain different amounts of silicon and manganese. S5 and S6, and $\mathrm{S} 7$ and S8 are based on S2 with manganese partly substituted by chromium and silicon replaced by aluminium, respectively.

All samples were annealed at $1000^{\circ} \mathrm{C}$ for 30 minutes and slowly cooled to $400^{\circ} \mathrm{C}$ before quenched in water. Afterwards, testable specimen geometries were cut by a cut-off grinding machine and austenitized at $1000^{\circ} \mathrm{C}$ for 15 minutes followed by quenching in water $\left(24^{\circ} \mathrm{C}\right)$. According to [6] this heat treatment dissolves all carbides and leads to full austenitization before quenching in similar high carbon steels.

Table 1 Chemical compositions of the steels tested

\begin{tabular}{|c|c|c|c|c|c|c|c|}
\hline Element & $\begin{array}{c}\mathbf{C} \\
(\mathbf{w t} \%)\end{array}$ & $\begin{array}{c}\mathbf{S i} \\
(\mathbf{w t} \%)\end{array}$ & $\begin{array}{c}\mathbf{M n} \\
\mathbf{( w t} \%)\end{array}$ & $\begin{array}{c}\mathbf{P} \\
(\mathbf{w t} \%)\end{array}$ & $\begin{array}{c}\mathbf{S} \\
\mathbf{( w t} \%)\end{array}$ & $\begin{array}{c}\mathbf{C r} \\
(\mathbf{w t} \%)\end{array}$ & $\begin{array}{c}\text { Al } \\
(\mathbf{w t} \%)\end{array}$ \\
\hline $\mathrm{S} 1$ & 1.25 & 3.22 & 2.3 & 0.013 & 0.012 & 0.2 & 0.01 \\
\hline $\mathrm{S} 2$ & 1.23 & 1.99 & 3.07 & 0.015 & 0.009 & 0.21 & 0.01 \\
\hline $\mathrm{S} 3$ & 1.24 & 3.2 & 3.33 & 0.017 & 0.013 & 0.21 & 0.01 \\
\hline $\mathrm{S} 4$ & 1.23 & 2.04 & 4.28 & 0.02 & 0.011 & 0.22 & 0.01 \\
\hline $\mathrm{S} 5$ & 1.22 & 1.62 & 2.27 & 0.015 & 0.011 & 1.21 & 0.01 \\
\hline S6 & 1.27 & 1.68 & 2.05 & 0.016 & 0.008 & 1.73 & 0.01 \\
\hline S7 & 1.25 & 0.71 & 3.03 & 0.018 & 0.006 & 0.22 & 0.99 \\
\hline S8 & 1.22 & 0.2 & 3.3 & 0.013 & 0.005 & 0.21 & 1.98 \\
\hline
\end{tabular}

Three commercial standard industrial-grade wear-resistant steels were used to compare the wear resistance of the MAS: X120Mn12 (fully austenitic Hadfield steel showing a low initial hardness), Hardox 450 and 30MnB5 (both fully martensitic steels having a high initial hardness).

\subsection{METHODS}

\subsubsection{SAMPLE PREPARATION}

Before abrasion tests and pre-wear XRD measurements, the samples were carefully ground and polished to prevent the formation of surface martensite. Surface preparation was carried out using semi-automatic grinding and polishing machine MECATECH 250 SPC (Presi). All parameters, including the applied forces for each step are given in Table 2. More information on the sample preparation is described elsewhere [10]. 
Table 2 Surface preparation procedure; SiC - Silicon carbide, $250 \mathrm{~mm}$ NT - Polishing cloth (PRESI), DP - Diamond polish (PRESI), Blue - Lubricant type "Blue" (Schmitz), OPS - Standard silica suspension (Struers)

\begin{tabular}{|c|c|c|c|c|c|c|c|c|c|}
\hline Grinding base & $\begin{array}{c}\text { SiC- } \\
\text { paper }\end{array}$ & $\begin{array}{c}\text { SiC- } \\
\text { paper }\end{array}$ & $\begin{array}{c}\text { SiC- } \\
\text { paper }\end{array}$ & $\begin{array}{c}\text { SiC- } \\
\text { paper }\end{array}$ & $\begin{array}{c}\text { SiC- } \\
\text { paper }\end{array}$ & $\begin{array}{c}250 \mathrm{~mm} \\
\text { NT }\end{array}$ & $\begin{array}{c}250 \mathrm{~mm} \\
\text { NT }\end{array}$ & $\begin{array}{c}250 \mathrm{~mm} \\
\text { NT }\end{array}$ & $250 \mathrm{~mm}$ NT \\
\hline Abrasive & $\mathrm{SiC}$ & $\mathrm{SiC}$ & $\mathrm{SiC}$ & $\mathrm{SiC}$ & $\mathrm{SiC}$ & $\mathrm{DP}$ & $\mathrm{DP}$ & $\mathrm{DP}$ & SiO2 \\
\hline Grain size $(\mu \mathrm{m})$ & 82 & 46 & 26 & 15 & 8 & 3 & 1 & 0.25 & 0.04 \\
\hline Lubricant & Water & Water & Water & Water & Water & Blue & Blue & Blue & 1 OPS : 1 Blue \\
\hline Head (rpm) & 150 & 150 & 150 & 150 & 150 & 100 & 100 & 100 & 100 \\
\hline Disk (rpm) & 250 & 250 & 250 & 250 & 250 & 150 & 150 & 150 & 150 \\
\hline Force (N) & 25 & 25 & 25 & 25 & 10 & $10 / 5 / 1$ & $10 / 5 / 1$ & $10 / 5 / 1$ & $10 / 5 / 1$ \\
\hline Time (min) & $2 \times 3$ & $2 \times 3$ & $2 \times 3$ & $2 \times 3$ & $2 \times 3$ & $3 \times 5$ & $3 \times 5$ & $3 \times 5$ & $3 \times 5$ \\
\hline
\end{tabular}

\subsubsection{ABRASION TESTS}

Two-body abrasion tests were carried out using NUS ISO 3 abrasion tester (Suga Test Instruments). SiC abrasive paper ( $46 \mu \mathrm{m}$ grain size; P320) attached to a rubber-covered aluminium wheel is pressed against the sample by lever action. The applied force was set to $16 \mathrm{~N}$. The sample is fixed in vertical movement and performs the horizontal reciprocating movement relative to the abrasive paper, while the wheel performs an incrementally rotating movement. One testing cycle consists of three consecutive wear cycles. Each wear cycle contains 400 strokes, which in turn consist of a reciprocating movement of $30 \mathrm{~mm}$ length each $(60 \mathrm{~mm}$ per stroke). Accordingly, $24 \mathrm{~m}$ of wear distance are covered for each wear cycle. The wheel rotates by 0.9 degrees after each stroke to have constantly unworn abrasive paper in contact with the sample. Therefore, after 400 strokes or 360 degrees, the abrasive paper was changed. The weight loss was measured after every wear cycle using an electronic balance $(0.1 \mathrm{mg}$ precision). A specific wear rate (SWR) was used to evaluate and compare the wear resistance of the steels. The SWR is defined in equation (1) as the mass loss $\Delta \mathrm{m}(\mathrm{mg})$ during wear divided by the product of force $F(N)$ and wear distance $d(\mathrm{~km})$.

$S W R=\frac{\Delta m(\mathrm{mg})}{F(N) \cdot d(\mathrm{~km})}$

\subsubsection{SUB-SURFACE CHARACTERIZATION}

XRD measurements were conducted using a D8 Discover diffractometer (Bruker) with Cu-radiation $(\lambda=0.154 \mathrm{~nm})$ in Bragg-Brentano geometry. $2.5^{\circ}$ soller slits were mounted on the primary and secondary tracks. A Ni-filter was used to reduce the $\mathrm{Cu}-\mathrm{K}_{\beta}$-radiation. The step size was set to $0.03^{\circ}$ at $3 \mathrm{~s}$ measuring time per step over the entire measuring range of $40-98^{\circ} 2$ Theta.

SEM (Ultra 55, Zeiss) was used for cross-section analyses and imaging of the wear tracks. To reveal the subsurface microstructures, the cross-sections of worn samples were prepared according to Table 2 and etched with $3 \%$ Nital afterwards. A nickel layer has been electrolytically coated to the worn surface to reduce edge rounding during polishing.

Hardness in pre- and post-wear condition was determined by the means of microhardness testing using hardness tester KB30S (KB Prüftechnik).

\section{RESULTS AND DISCUSSION}

\subsection{ABRASION TEST RESULTS}

The pre- and post-wear hardness and the SWR measured are given in Table 3. The varying pre-wear hardness of the steels are explained by different amounts of martensite and austenite in the initial microstructure and 
due to different carbon concentrations in the case of fully martensitic Hardox 450 (around $0.2 \mathrm{wt} \%$ carbon) and $30 \mathrm{MnB} 5$ (around $0.3 \mathrm{wt} \%$ carbon). Since $\mathrm{X} 120 \mathrm{Mn} 12$ has a fully austenitic microstructure the hardness is the lowest. The MAS lie in between austenitic and martensitic steels.

Hardox 450 exhibits the highest SWR (SWR $=30 \mathrm{mg} \mathrm{N}^{-1} \mathrm{~km}^{-1}$ ), followed by X120Mn12 (SWR = 20.4 mg N$\left.{ }^{1} \mathrm{~km}^{-1}\right)$ and $30 \mathrm{MnB5}\left(\mathrm{SWR}=19.1 \mathrm{mg} \mathrm{N}^{-1} \mathrm{~km}^{-1}\right)$. Generally, the MAS exhibit a higher two-body abrasive wear resistance as compared to the commercial steels. The least SWR in MAS is achieved by S8 ( $\mathrm{SWR}=16.2 \mathrm{mg} \mathrm{N}^{-1} \mathrm{~km}^{-1}$ ), which is still better than the best commercial steel. S1 showed the lowest SWR $\left(\mathrm{SWR}=5.6 \mathrm{mg} \mathrm{N}^{-1} \mathrm{~km}^{-1}\right)$ which indicates a 3.4 times higher wear resistance as compared to $30 \mathrm{MnB}$.

Table 3 Pre- and post-wear hardness, increase in hardness during wear and SWR measured

\begin{tabular}{|c|c|c|c|c|}
\hline Steel & $\begin{array}{c}\text { Pre-wear hardness } \\
\mathbf{( H V )}\end{array}$ & $\begin{array}{c}\text { Post-wear hardness } \\
\mathbf{( H V )}\end{array}$ & $\begin{array}{c}\text { Hardness increase } \\
\mathbf{( H V})\end{array}$ & $\begin{array}{c}\text { SWR } \\
\left(\mathbf{m g ~ N}^{\mathbf{- 1}} \mathbf{k m}^{-\mathbf{1}} \mathbf{)}\right.\end{array}$ \\
\hline X120Mn12 & $233 \pm 13$ & $688 \pm 0$ & 455 & $20.4 \pm 1.6$ \\
\hline Hardox 450 & $474 \pm 39$ & $478 \pm 13$ & 4 & $30 \pm 2.6$ \\
\hline 30MnB5 & $519 \pm 46$ & $774 \pm 254$ & 255 & $19.1 \pm 0.5$ \\
\hline S1 & $407 \pm 67$ & $912 \pm 140$ & 505 & $5.6 \pm 0.6$ \\
\hline S2 & $247 \pm 27$ & $944 \pm 206$ & 697 & $6.7 \pm 1$ \\
\hline S3 & $344 \pm 18$ & $842 \pm 123$ & 498 & $8.5 \pm 0.7$ \\
\hline S4 & $237 \pm 10$ & $1003 \pm 121$ & 766 & $8.9 \pm 1$ \\
\hline S5 & $294 \pm 22$ & $1105 \pm 130$ & 811 & $10.3 \pm 0.1$ \\
\hline S6 & $502 \pm 34$ & $1156 \pm 82$ & 654 & $11.2 \pm 1$ \\
\hline S7 & $483 \pm 1$ & $1231 \pm 183$ & 748 & $9.5 \pm 0.6$ \\
\hline S8 & $370 \pm 62$ & $877 \pm 139$ & 507 & 16.2 \\
\hline
\end{tabular}

Figure 1a shows the measured SWR as a function of the post-wear hardness. It becomes evident, that the highest hardness achieved is not related to the lowest SWR. Rather, it seems like there is an optimum postwear hardness between 900 and $1000 \mathrm{HV}$. Further, Figure 1b shows that the SWR is more related to the increase in hardness during wear tests: The higher the hardness increase, the lower the SWR. It can also be seen that the lowest SWR achieved (S1, S2, S3) are not consistent with the highest hardness/hardness increase and that other mechanisms must contribute to wear resistance.
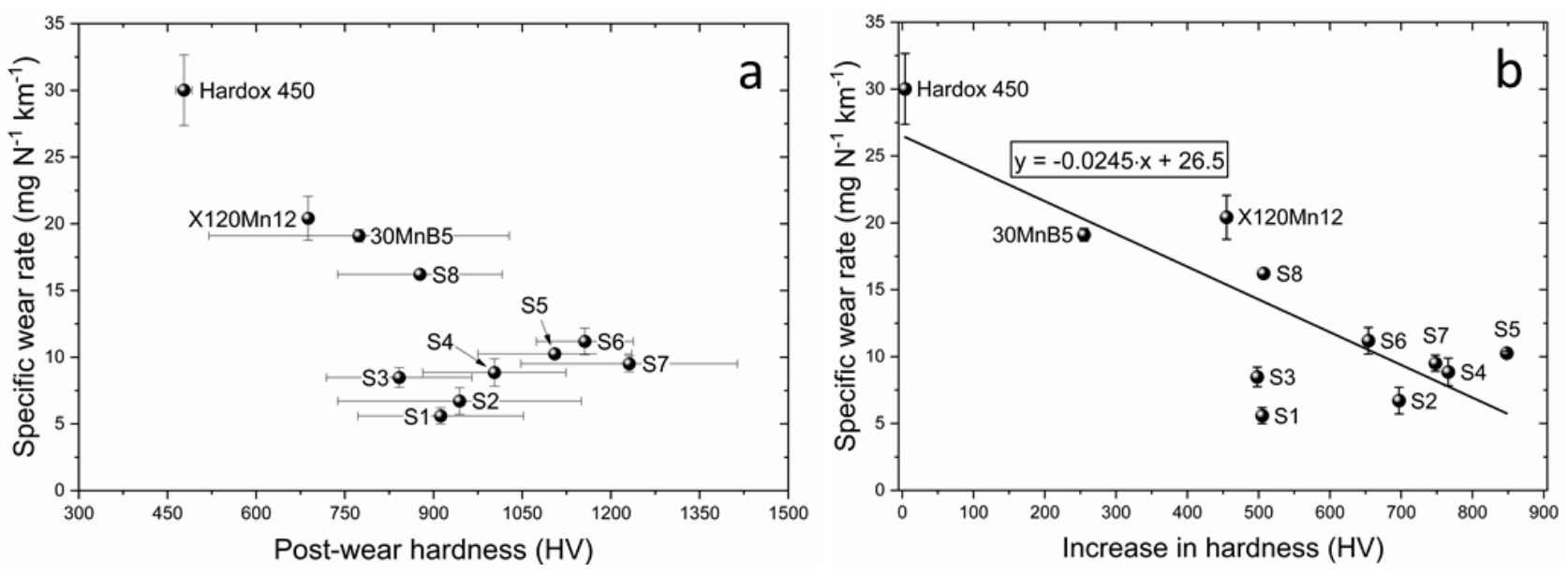

Figure 1 Measured SWR as a function of post-wear hardness (a) and increase in hardness (b) 


\subsection{SUB-SURFACE CHARACTERIZATION}

Figure $2 \mathbf{a}$ shows the etched cross-section of the sub-surface region of the worn S4 steel. The initial microstructure consists of austenite $(\mathrm{\gamma})$ and thermally induced martensite $\left(\alpha^{\prime}\right)$. After wear tests a layer is visible (between the Ni-coating and the dotted line) immediately below the surface, which is characterized by the presence of persistent slip bands (PSB). Within the layer, the thermally induced martensite is fractured. The near-surface regions of the worn steels S1, S2, S3, S6 and S7 did exhibit the same characteristics as those in steels S4 and S5 (Figure 2a and c). However, no PSB or similar deformation structures were visible in the near-surface region of the worn S8 steel (Figure 2b). Therefore, the higher SWR of S8 compared to the other MAS is due to the missing PSB layer.

In addition to the visible PSB structures a macroscopic deformation in the form of a chip (circled) is recognizable in Figure 2c. It seems like the chip has formed and has later been pressed again on the surface, accompanied by the creation of a distinct deformation zone with high PSB density underneath the chip.

The wear tracks of the S5 steel shown in Figure 2d illustrate the surface of all MAS specimens after wear. In all MAS, the material removal from the surface is primarily caused by wedge formation due to micro-ploughing, micro-cutting, micro-fatigue and delamination. A correlation between chemical composition and the presence of a specific wear mechanism could not be observed. The XRD results, Figure 3, show that the measured intensity of the austenitic phase decreases and that of the ferritic phase increases during wear tests. The combination of the measured hardness and the XRD results leads to the conclusion that all tested MAS undergo austenite to $\alpha^{\prime}$-martensite transformation during wear. The observed PSB possibly act as nucleation sites, because intersections of slip bands can serve as nucleation sites for martensite [11-13]. The sub-surface region of steel S8 undergoes a transformation from austenite to $\alpha^{\prime}$-martensite as shown by XRD which is in contrast to the mentioned assumption of martensite nucleation at slip band intersections. It is possible that the layer cannot be seen due to poor etching or better resistance due to the alloy composition (high Aluminium content) or the layer is not very pronounced. However, it can be concluded that both, martensite formation and plastic deformation in the form of a sufficiently developed PSB layer within the sub-surface region, is necessary to obtain a low SWR.

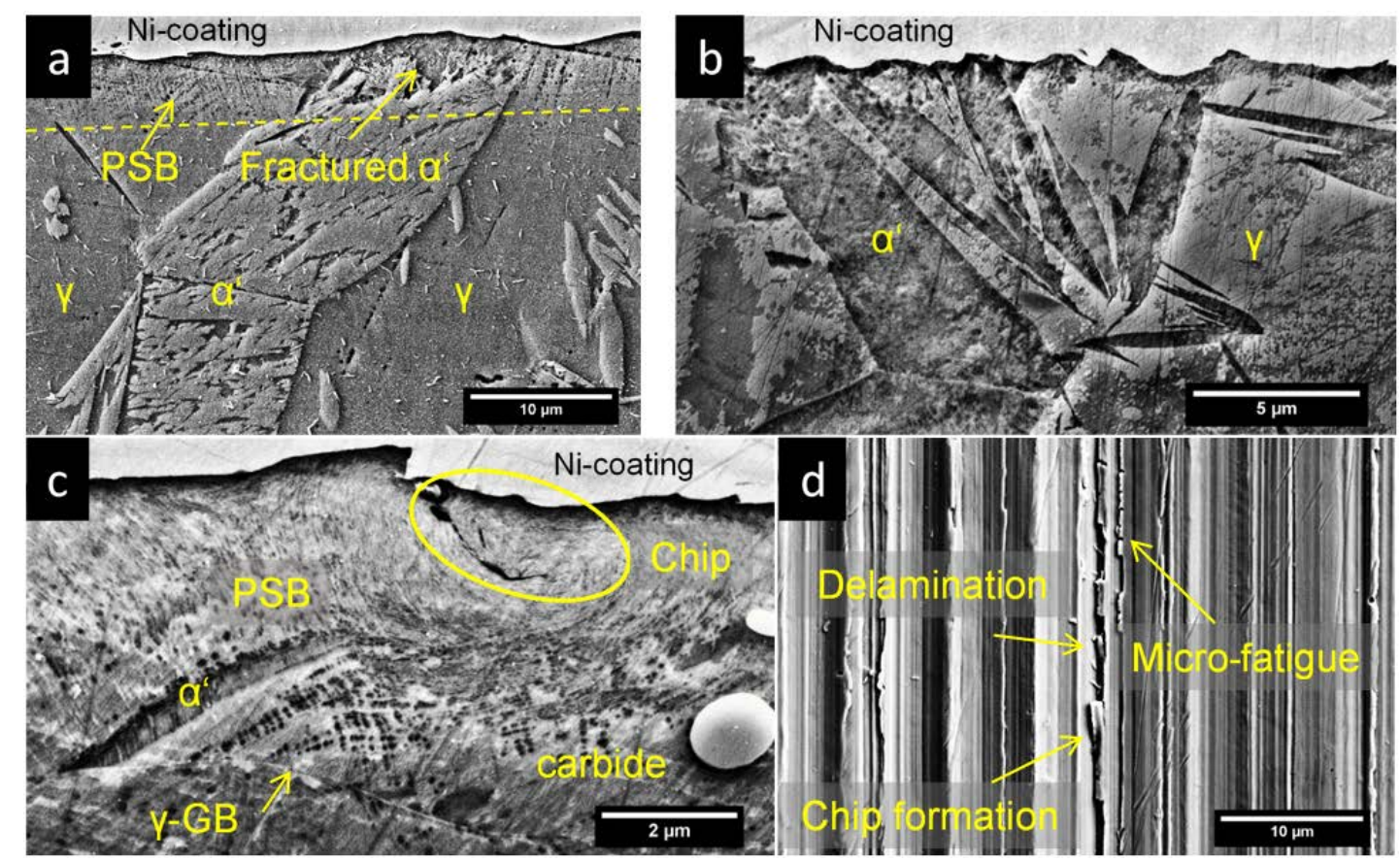

Figure 1 SEM micrographs of etched cross sections of worn samples (a - S4; b - S8; c - S5) and wear track (d) of sample S5 

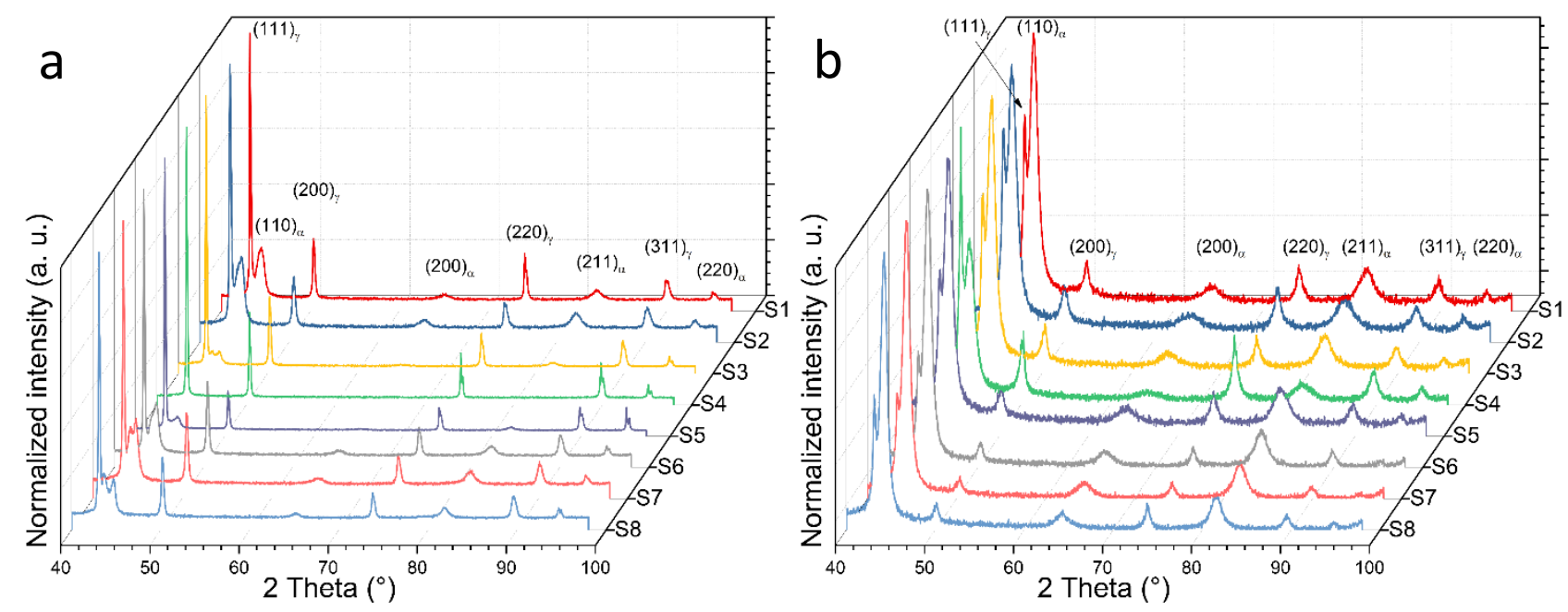

Figure 2 X-ray diffraction patterns of MAS in pre-wear (a) and post-wear condition

\section{CONCLUSION}

This research analyzed the two-body abrasion wear behavior and the sub-surface microstructure after wear of some high-carbon MAS by comparing their specific wear rates and post-wear hardness with three commercial wear-resistant steels. Following conclusions can be made:

- $\quad$ All tested MAS present better wear resistance than the tested commercial steels.

- The best wear resistance is found at an increase in hardness during wear to 900 to $1000 \mathrm{HV}$. At lower and higher values, the wear resistance tends to decrease.

- Hardness increase in MAS is related to the deformation-induced formation of martensite at the surface and work hardening of the near-surface region.

- The best wear resistance is achieved when martensitic transformation is accompanied by work hardening of the near-surface region.

\section{REFERENCES}

[1] BLECK, W.; GUO, X.; MA, Y. The TRIP effect and its application in cold formable sheet steels. Steel research international. 2017, vol. 88, no. 10, p. 1700218.

[2] BHADESHIA, H. K. D. H.; HONEYCOMBE, R. Steels: microstructure and properties. Butterworth-Heinemann. 2017.

[3] FARGAS, G.; ROA, J. J.; MATEO, A. Influence of pre-existing martensite on the wear resistance of metastable austenitic stainless steels. Wear. 2016, vol. 364, pp. 40-47.

[4] VALIZADEH MOGHADDAM, $P$, et al. Influence of fracture toughness on two-body abrasive wear of nanostructured carbide-free bainitic steels. Wear. 2020, vol. 460, p. 203484.

[5] HESSE, O. et al. Investigation on friction surface of high-carbon low-alloyed steel after abrasive wear. Problems of Tribology. 2019, vol. 24, no. 3/93, pp. 22-28.

[6] EFREMENKO, V. G., et al. Two-body abrasion resistance of high-carbon high-silicon steel: Metastable austenite vs nanostructured bainite. Wear. 2019, vol. 418, pp. 24-35.

[7] LAl, Jian-ping, et al. Two-body abrasion resistance of high carbon steel treated by quenching-partitioningtempering process. Wear. 2019, vol. 440, p. 203096.

[8] BAKSHI, S. Das; SHIPWAY, P. H.; BHADESHIA, H. K. D. H. Three-body abrasive wear of fine pearlite, nanostructured bainite and martensite. Wear. 2013, vol. 308, no. 1-2, pp. 46-53. 
[9] CHINTHA, A. R. Metallurgical aspects of steels designed to resist abrasion, and impact-abrasion wear. Materials Science and Technology. 2019, vol. 35. no. 10, pp. 1133-1148.

[10] FRIEDRICH, T. Characterisation of microstructures and phase contents using electron-and $X$-ray diffraction techniques - Investigations of the TRIP effect on high-carbon, high-silicon steel. 2018. Master Thesis

[11] TALONEN, J.; HÄNNINEN, H. Formation of shear bands and strain-induced martensite during plastic deformation of metastable austenitic stainless steels. Acta materialia. 2007, vol. 55, no. 18, pp. 6108-6118.

[12] KRUPP, U., et al. On the mechanism of martensite formation during short fatigue crack propagation in austenitic stainless steel: experimental identification and modelling concept. In: Proceedings of the 13th International Conference on Fracture. Beijing, China, 2013.

[13] WANG, J. L., et al. Characteristics of nucleation and transformation sequence in deformation-induced martensitic transformation. Materials Characterization. 2020, vol. 163, p. 110234. 